\title{
Gender differences and quality of life in atrial fibrillation: The mediating role of depression
}

\author{
Lephuong Ong ${ }^{\mathrm{a}, *}$, Jane Irvine ${ }^{\mathrm{a}, \mathrm{b}}$, Robert Nolan ${ }^{\mathrm{a}, \mathrm{b}}$, Robert Cribbie ${ }^{\mathrm{a}}$, \\ Louise Harris $^{\mathrm{b}}$, David Newman ${ }^{\mathrm{c}}$, Iqwal Mangat ${ }^{\mathrm{c}}$, Paul Dorian ${ }^{\mathrm{d}}$ \\ ${ }^{\mathrm{a}}$ Department of Psychology, York University, Toronto, Canada \\ ${ }^{\mathrm{b}}$ Toronto General Hospital, University Health Network, Toronto, Canada \\ ${ }^{\mathrm{c}}$ Division of Cardiology, Sunnybrook and Women's College Health Sciences Centre, Toronto, Canada \\ ${ }^{\mathrm{d}}$ Department of Medicine, St. Michael's Hospital, University of Toronto, Toronto, Canada
}

Received 26 May 2005

\begin{abstract}
Objective: This study investigated gender differences, depression, and health-related quality of life (QoL) in a crosssectional sample of patients with atrial fibrillation (AF). Methods: This cross-sectional study involved a convenience sample of AF patients from two tertiary-care clinics in Toronto, Canada. Ninety-three AF patients completed psychometrically validated measures of generic QoL and depression. Mediation analyses evaluated the relationship between gender and QoL using depression as mediating variable. Results: Relative to male patients, female patients reported lower physical, but not mental, QoL. Gender was associated with both depression and
\end{abstract}

physical QoL, while depression was correlated with poorer physical QoL. Path analyses demonstrated that depression significantly mediated the relationship between gender and physical QoL. Conclusion: Among AF patients, female patients report lower physical QoL relative to male patients, and this relationship may be mediated by self-reported symptoms of depression. Albeit correlational, the findings underscore the need to develop a better understanding of the role of depression in physical QoL, especially when considering the burden of AF in women.

(C) 2006 Elsevier Inc. All rights reserved.

Keywords: Atrial fibrillation; Depression; Gender; Quality of life

\section{Introduction}

Atrial fibrillation (AF), the most common heart rhythm disturbance, accounts for one third of all patients hospitalized for arrhythmia [1-3]. It is associated with considerable morbidity and mortality $[1,2,4]$, as well as with significant impairments in health-related quality of life (QoL) in terms of physical, social, emotional, and mental functioning [5-8]. AF patients report greater QoL impairments relative to patients with congestive heart failure or myocardial infarction (MI) [5,9]. QoL impairments persist

* Corresponding author. Department of Psychology, York University, 297 Behavioral Sciences Building, 4700 Keele Street, Toronto, Ontario, Canada M3J 1P3. Tel.: +1 416736 5115; fax: +1 4167365814.

E-mail address: lephuong@yorku.ca (L. Ong). even in the absence of structural heart disease [7,10], and it has been found to be unrelated or only weakly correlated with indices of disease burden, frequency of episodes, illness duration, functional class, and ventricular function [7,11].

Gender differences in QoL have been demonstrated and indicate that female patients report worse QoL relative to male patients [11-15]. Female patients are also more likely than male patients to report more AF-related complaints, such as greater frequency and severity of symptoms $[13,15,16]$. However, it is unclear whether these discrepancies are a function of differential illness-reporting styles between genders, divergent illness evaluations, or whether female patients actually experience more frequent and severe AF symptoms. The latter seems plausible if female patients are older and have more severe comorbidities than male patients. In Paquette et al.'s study [13], female patients 
were older and were more likely to have hypertension, but after these factors had been controlled, female patients still reported greater impairments in physical health and functional capacity than male patients.

Taken together, available research suggests that (a) the QoL of AF patients is impaired relative to other cardiac patient groups; (b) impairments are present, irrespective of underlying heart disease severity; and (c) female patients report poorer QoL than male patients. Despite these associations, little is known of the factors that might explain the variability in $\mathrm{QoL}$ in $\mathrm{AF}$, particularly with respect to observed gender differences. One set of factors that might be important to examine is psychological factors. To date, only one study has examined personality factors (i.e., somatization) that contribute to QoL differences between men and women with AF, yielding positive support for the role of nondisease variables [13]. Additional research is needed to identify psychosocial factors that may be associated with poorer QoL in female patients.

One variable that has emerged as a robust predictor of QoL is depression. Among patients with coronary artery disease and congestive heart failure, depression has been found to be a stronger predictor of poor health status than measures of disease severity, such as ejection fraction, stress-induced ischemia, and New York Heart Class $[17,18]$. The severity of depression has predicted greater symptom burden, physical limitations, worse overall health, and poor QoL [17]. Baseline depression scores have also been linked with QoL 1 year after MI [19,20].

Since prevalence rates for depression are higher among women [21,22], coupled with associations between depression and poor QoL, one might speculate whether any gender differences in QoL in AF are mediated by symptoms of depression. This study pursued this line of inquiry and investigated the relationships between gender, depression, and QoL. It was hypothesized that female patients would report poorer mental and physical QoL relative to male patients, and that self-reported symptoms of depression would be associated with poorer QoL. Furthermore, selfreported symptoms of depression were proposed to mediate the association between gender and QoL.

\section{Methods}

\section{Participants}

This cross-sectional study involved a convenience sample of AF patients from two tertiary care clinics in Toronto, Canada. The research ethics boards at each site reviewed and approved the study procedure. The methods of this study have been reported in detail [23]. In brief, eligible participants were identified from the medical charts in each clinic. Patients who provided informed consent were mailed a questionnaire package that included study measures. Patients who did not return their questionnaires within a 2-week period were given up to two reminder telephone calls.

Patients who were 18 years of age or older and with a primary diagnosis of AF were included. Patients with concurrent heart disease were included, provided that valvular disease was mild or absent, and ejection fraction was unimpaired (i.e., Class I or II). Patients who: (a) could not read or understand English; (b) had cognitive deficits documented in their medical charts; (c) had a history of severe psychiatric illness (e.g., schizoaffective disorder, bipolar disorder, and schizophrenia); (d) had received an atrial or implantable cardioverter defibrillator; or (e) acquired AF as a result of cardiac surgery or other medical conditions (e.g., hyperthyroidism) were excluded.

\section{Clinical characteristics}

Information on illness duration, cardiovascular history (e.g., coronary heart disease, valve disease, and hypertension), ejection fraction, noncardiac medical history (e.g., diabetes and cancer), cardioversion, and medications was obtained via medical chart review.

\section{Study questionnaires}

\section{University of Toronto Atrial Fibrillation Severity Scale}

This 14-item disease-specific scale was locally constructed to evaluate patient-perceived arrhythmia burden. Data on AF episode frequency and duration were derived from the AF burden subscale, which has an internal reliability of .94 [11,24]. Scores range from 1 to 10 , where higher scores indicate greater frequency and duration.

\section{Medical Outcomes Study Short-Form 36 Health Survey (SF-36)}

Generic mental and physical QoL was assessed with this widely used scale, which measures physical functioning, physical role limitation, bodily pain, general health, vitality, social functioning, emotional role limitation, and mental health [25]. Subscales are combined to form two composite scores: physical component summary (PCS) and mental component summary (MCS). The PCS evaluates energy levels and interference to social, occupational, or role functioning due to physical health status and bodily pain. The MCS measures positive affect and limitations to social, occupational, or role functioning due to emotional distress. The internal reliability values for the PCS and MCS are reported to be .93 and .88 , respectively [26]. Scores range from 0 to 100 , with higher values indicating better functioning and fewer limitations.

\section{Hospital Anxiety and Depression Scale (HADS)}

This 14-item scale is both reliable and valid, and was developed to screen for the presence and severity of anxiety and depression in medical settings since it omits somatic symptoms of depression (e.g., fatigue and appetite changes) that may lead to false-positive findings in medical patients 
[27]. The internal reliability for the depression subscale has been reported to be .86 [28]. Ratings are made on a 4-point Likert scale (e.g., $0=$ not at all, $3=$ definitely) and summed to produce scores between 0 and 21 . Higher scores signify more depressive symptoms. Snaith and Zigmond [29] suggest that scores $\geq 8$ indicate possible depression and that scores $\geq 11$ indicate probable depression. Recent work indicates that the cutoff score of 8 provides an ideal balance between specificity and sensitivity [30].

\section{Data analysis}

Univariate relationships were assessed using Welch's $t$ test, Pearson's $r$, and $\chi^{2}$ statistics. To demonstrate mediation, regression analyses were conducted to establish that: (a) the independent variable influences both the dependent variable and the mediator; and (b) the mediator has an effect on the dependent variable [31]. Mediation is demonstrated if the independent variable no longer affects the dependent variable once the mediator is added to the model [31]. The significance of mediation effect was assessed using the Sobel test [32].

Data screening was performed as described in Tabachnick and Fidell [33]. Reflect and square root transformations corrected the negatively skewed SF-36 MCS and PCS distributions. A logarithmic transform corrected positively skewed HADS scores. Demographic and medical variables met criteria for a confounding variable if they were univariately related to both the independent variable and the dependent variable of interest at $\alpha<10$. Control variables were entered at the first step of the multivariate model. Cronbach's $\alpha$ was computed for each scale to determine reliability.

Missing data were random (i.e., did not vary with demographic characteristics or study variables) and were imputed with mean scores if at least $50 \%$ of scale items were answered [34]. This procedure left six cases with missing data, which were imputed with stochastic regression [33].

\section{Results}

\section{Sample characteristics}

Of 189 eligible patients, questionnaires were mailed to 125 patients who provided informed consent. Of these, 99 packages were returned ( $79 \%$ participation rate), and

Table 1

Selected demographic characteristics of patients, by gender

\begin{tabular}{llll}
\hline & Female $(n=32)$ & Male $(n=61)$ & $P$ \\
\hline Age (years; mean \pm S.E.M.) & $62.72 \pm 2.27$ & $61.44 \pm 1.50$ & .64 \\
Married/cohabiting (\%) & 65.63 & 88.52 & .008 \\
Postsecondary education (\%) & 75.00 & 83.61 & .32 \\
Employment (\%) & 40.63 & 59.02 & .09 \\
Illness duration (years; & $8.72 \pm 1.32$ & $6.79 \pm .69$ & .20 \\
$\quad$ & & & \\
\hline
\end{tabular}

Table 2

Clinical characteristics of patients, by gender

\begin{tabular}{|c|c|c|c|}
\hline & Female $(n=32)$ & Male $(n=61)$ & $P$ \\
\hline $\begin{array}{l}\text { Illness duration (years; } \\
\text { mean } \pm \text { S.E.M.) }\end{array}$ & $8.72 \pm 1.32$ & $6.79 \pm .69$ & .20 \\
\hline Paroxysmal AF (\%) & 71.88 & 52.46 & .07 \\
\hline Lone AF (\%) & 43.75 & 44.26 & .96 \\
\hline Coronary artery disease (\%) & 6.25 & 14.75 & .23 \\
\hline Valvular heart disease $(\%)$ & 6.25 & 3.28 & .50 \\
\hline Hypertension (\%) & 46.88 & 45.90 & .93 \\
\hline Warfarin (\%) & 53.13 & 70.49 & .10 \\
\hline Amiodarone (\%) & 21.88 & 19.67 & .80 \\
\hline Sotalol $(\%)$ & 3.13 & 11.48 & .17 \\
\hline$\beta$-Blockers $(\%)$ & 56.25 & 54.10 & .84 \\
\hline Antidepressants (\%) & 15.63 & 3.28 & .032 \\
\hline Prior cardioversion ${ }^{\mathrm{a}}(\%)$ & 43.75 & 65.57 & .043 \\
\hline
\end{tabular}

a At least one prior cardioversion.

6 were excluded due to severe ventricular dysfunction $(n=1)$, hyperthyroidism $(n=1)$, participant attrition $(n=3)$, and lack of written English comprehension $(n=1)$. Thus, 93 adults were included in the study (mean age $=61.88 \pm$ 12.04 years). Participants tended to be male (66\%) and fairly highly educated (see Table 1). Fifty-three percent of the sample was employed at the time of assessment. No gender differences were found for age $[t(58.02)=1.28$, $P=.64]$, education $\left[\chi^{2}(1)=1.00, P=.32\right]$, or employment status $\left[\chi^{2}(1)=2.85, P=.09\right]$. More male patients were married or cohabiting $\left[\chi^{2}(1)=7.05, P=.008\right]$.

The mean illness duration for all participants was $7.45 \pm 6.22$ years and did not differ by gender $[t(48.35)=$ $-1.30, P=.20$; see Table 2]. Twenty-one percent reported having $\mathrm{AF}$ episodes more than once per week, $16 \%$ had episodes between once per week and once per month, and $32 \%$ had episodes less than once per month. The mean episode duration was $1 \mathrm{~h}$ or less in $25 \%$, several hours in $25 \%$, and 1 day or more in $14 \%$. There were no gender differences in perceived episode frequency $[t(71.01)=-.65$, $P=.52]$; however, female patients reported lengthier episodes $[t(51.92)=-3.57, P=.001]$. Gender differences on AF pattern (persistent/permanent vs. paroxysmal) approached significance $\left[\chi^{2}(1)=3.27, P=.07\right]$. More male patients had at least one prior cardioversion $\left[\chi^{2}(1)=4.11, P=.043\right]$. No gender differences were found for the presence of any heart disease $\left[\chi^{2}(1)=1.74, P=.18\right]$, hypertension $\left[\chi^{2}(1)=0.008\right.$, $P=.93$ ], or cardiovascular medications [e.g., warfarin: $\chi^{2}(1)=2.77, P=.10 ;$ amiodarone: $\chi^{2}(1)=0.063, P=.80$; sotalol: $\chi^{2}(1)=1.86, P=.17 ; \beta$-blockers: $\chi^{2}(1)=0.039$,

Table 3

Prevalence of depression for all patients $(N=93)$

\begin{tabular}{llll}
\hline Depression & $\begin{array}{l}\text { Female }(n=32) \\
{[n(\%)]}\end{array}$ & $\begin{array}{l}\text { Male }(n=61) \\
{[n(\%)]}\end{array}$ & $\begin{array}{l}\text { All patients } \\
{[n(\%)]}\end{array}$ \\
\hline Possible $^{\mathrm{a}}$ & $4(12.5)$ & $6(9.8)$ & $10(10.8)$ \\
Probable $^{\mathrm{b}}$ & $3(9.4)$ & $0(0.0)$ & $3(3.2)$ \\
\hline
\end{tabular}

${ }^{\text {a }}$ Using a cutoff score of $\geq 8$.

${ }^{\mathrm{b}}$ Using a cutoff score of $\geq 11$. 
$P=$.84]. More female patients were taking antidepressants $\left[\chi^{2}(1)=4.60, P=.032\right]$.

\section{Depression}

Reliability analyses indicate that Cronbach's $\alpha=.78$ for the HADS depression subscale. Using a cutoff score of 8 , most participants $(89 \%)$ did not have significant symptoms of depression (see Table 3 for the prevalence of depression, by gender). As expected, female patients reported higher depression scores relative to male patients $[t(63.64)=-2.58$, $P=.012$; see Table 4]. Depression was related to lower physical $(r=-.58, P<.001)$ and mental QoL $(r=-.51$, $P<.001)$, but did not vary as a function of age $(r=.14, P=.17)$.

\section{QoL}

Cronbach's $\alpha=.85$ for both mental and physical QoL, indicating good reliability. Female patients reported significantly lower physical QoL $[t(60.70)=2.15, P=.003]$ relative to male patients. No gender differences were found on mental QoL $[t(48.04)=1.16, P=.25]$.

\section{Mediation analysis}

Univariate analyses revealed gender differences for marital status, AF pattern, AF duration, prior cardioversion, and antidepressant use (all $P<.10$ ). However, none of these variables was concurrently related to any of the dependent measures and, thus, did not meet criteria for a confounding variable (all $P>.10$ ). In contrast, employment status [depression: $t(85.83)=3.70, P<.001$; physical QoL: $t(84.70)=$ $-4.32, P<.001$ ], prior MI [depression: $t(6.79)=-2.83$, $P=.03$; physical QoL: $t(5.80)=2.98, P=.03]$, and noncardiac medical history [gender: $\chi^{2}(1)=12.51, P<.001$; physical QoL: $t(80.90)=4.33, P<.001]$ were controlled for in the regression model.

Compared to male patients, female patients had higher depression scores $(\beta=.26, P=.012)$ and poorer physical QoL $(\beta=-.22, P=.032)$. Depression was negatively correlated with physical QoL $(\beta=-.48, P<.001)$. When depression was entered as a mediator into the model, the relationship between gender and physical QoL was reduced $(\beta=-.12, P=.18)$, while the relationship between depression and physical QoL remained significant $(\beta=-.44, P<.001)$. In addition, the indirect effect between gender and physical QoL, through

Table 4

Descriptive statistics for all patients $(N=93)$, by gender

\begin{tabular}{llll}
\hline & $\begin{array}{l}\text { Female }(n=32) \\
(\text { mean } \pm \text { S.E.M. })\end{array}$ & $\begin{array}{l}\text { Male }(n=61) \\
(\text { mean } \pm \text { S.E.M. })\end{array}$ & $P$ \\
\hline Physical QoL $^{\mathrm{a}}$ & $40.69 \pm 1.89$ & $47.73 \pm 1.20$ & .003 \\
Mental QoL $^{\mathrm{a}}$ & $50.67 \pm 1.76$ & $53.48 \pm .81$ & .25 \\
Depression $^{\mathrm{b}}$ & $4.19 \pm .63$ & $2.61 \pm .31$ & .012 \\
\hline
\end{tabular}

a Higher scores indicate better health-related QoL.

b Higher scores indicate more depressive symptoms.

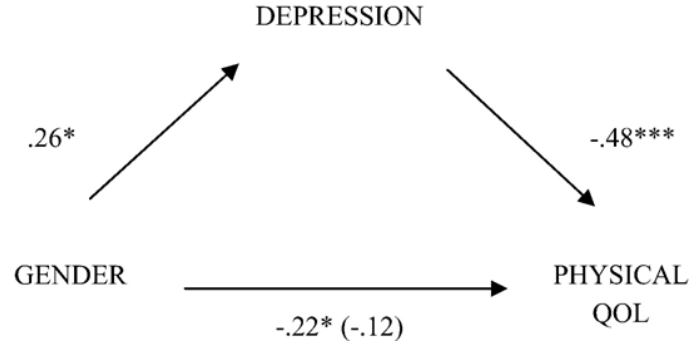

Fig. 1. Mediation model relating gender, depression, and physical QoL. Values represent standardized regression coefficients. The value inside the square brackets denotes the effect of gender on physical QoL, with depression as mediator. $* P<.05 ; * * * P<.001$.

depression, was significant (Sobel $z=-2.31, P=.021$; $R^{2}=.43$; see Fig. 1). Taken together, the results suggest that the relationship between gender and physical QoL may be mediated by self-reported symptoms of depression.

\section{Discussion}

This study investigated the nature of gender differences in QoL in AF patients and explored whether depression mediated the effects of gender on QoL. In this sample, male patients' mental and physical QoL scores are consistent with age-matched Canadian national normative values for the SF-36 [35]. Female patients also scored within the national norm for mental QoL but scored almost 1 S.D. below the national norm for physical QoL. Gender differences in physical and mental QoL scores are comparable to those of a published AF cohort [13].

Approximately $11 \%$ of our total sample met criteria for possible depression, which is slightly lower than the 14.4-14.6\% reported by Stordal et al. [36] in their population study. Their study [36] also suggests that HADS scores increase with age, although we did not find that association in our sample. Mean depression scores are consistent with previous work involving AF patients with patient-activated atrial defibrillators [37] and post-MI patients $[19,38,39]$ but were somewhat lower than scores reported by patients with implantable defibrillators [40]. This latter finding is perhaps not surprising as AF patients without implanted defibrillators are not faced with the stressful experience of unpredictable defibrillator shocks.

As hypothesized, AF has a greater impact on self-reported physical QoL in female patients than in male patients, despite similarities in age, cardiac history, ejection fraction, type of AF, AF episode frequency, and cardiac medications. Thus, it may be that female patients have a style of responding to or perceiving AF that is correlated with poor physical QoL outcomes. For instance, women may be more likely to perceive episodes of fibrillation or symptoms of their arrhythmia as more distressful, burdensome, or intrusive than men, which might lead to a greater attunement or preoccupation with AF symptoms. Previous work is consistent with this possibility, demonstrating that female 
patients had a greater tendency than male patients to amplify their physical symptoms [13], which may lead to heightened health-related distress. In contrast, no gender differences were found with respect to perceived mental QoL. This pattern of findings corroborates with the results of previous investigations $[13,14]$ that have demonstrated greater impairments in physical functioning, but not in terms of mental functioning, in female patients relative to male patients.

Self-reported symptoms of depression were found to be associated with poorer physical and mental QoL. To our knowledge, this is the first study to show this association in AF patients, and it is congruent with recent studies linking depression to poorer physical QoL in coronary artery disease [17] and post-MI [41]. Recent longitudinal data also show that depressive symptoms following a cardiac event contribute to future perceptions of QoL [20]. It is conceivable that depression might contribute to poorer mental and physical QoL through related cognitive and behavioral processes. For instance, depressed mood may increase perceptions of arrhythmia burden, while anhedonia may cause patients to behaviorally disengage from daily activities. Each of these processes may further fuel low mood and may perpetuate a vicious cycle of depressive symptoms and poor QoL.

Self-reported depressive symptoms significantly mediated the relationship between gender and physical QoL, and accounted for $43 \%$ of the variance in QoL. Hence, it appears that the relatively increased susceptibility of female patients to depressive symptoms might be a major contributing factor to their poorer perceived physical QoL compared to male patients. While the mediation model accounted for a considerable portion of the variance in physical QoL, it is likely that there are multiple mediating factors and that depression accounts for just one aspect of the association between gender and physical QoL. As the mean depression scores of the sample were lower than published cutoff scores recommended for probable depression [28], the results illustrate that even subclinical levels of depression may adversely affect QoL.

Although our findings provide important insights into gender differences in the QoL of AF patients, several limitations must be noted. First, all participants were recruited from highly specialized tertiary care clinics. These patients may differ from patients seen in general cardiology practice along many dimensions such as AF severity, treatment resistance, and distress factors that may ultimately affect perceived QoL. It is therefore difficult to determine whether study findings are applicable to AF patients seen in community cardiology practice. Second, the results are based on a convenience sample, which potentially limits the generalizability of the findings and increases the risk of selection bias. However, our results are still informative of the QoL of patients who attend specialty arrhythmia clinics. Third, the relatively small sample limits the number of confounding variables that can be considered in the multivariable model. Fourth, significantly more male patients tended to be married and more female patients were taking antidepressants, which might indicate potential selection bias. However, observed gender differences in marital status are representative of the general population of Canadians between the fifth and the seventh decades of life [42]. Similarly, gender differences in antidepressant usage are a natural reflection of the higher prevalence of depressive symptoms among female patients $[21,43,44]$. Finally, the cross-sectional design of the current study renders it impossible to establish causal relationships between study variables. Studies employing a prospective longitudinal design are needed to elucidate the direction of the relationships between gender, depression, and QoL.

\section{Acknowledgments}

This research was supported by an Ontario Graduate Scholarship and by a Social Sciences and Humanities Research Council Doctoral Fellowship awarded to the first author. We wish to thank all patients who participated in this study, as well as the attending staff of the arrhythmia clinics at the Toronto General Hospital and St. Michael's Hospital.

\section{References}

[1] Benjamin EJ, Wolf PA, D’Agostino RB, Silbershatz H, Kannel WB, Levy D. Impact of atrial fibrillation on the risk of death: the Framingham Heart Study. Circulation 1998;98:946-52.

[2] Wolf PA, Mitchell JB, Baker CS, Kannel WB, D'Agostino RB Impact of atrial fibrillation on mortality, stroke, and medical costs. Arch Intern Med 1998;158:229-34

[3] Fuster V, Ryden LE, Asinger RW, Cannom DS, Crijns HJ, Frye RL, Halperin JL, Kay GN, Klein WW, Levy S, McNamara RL, Prystowsky EN, Wann LS, Wyse DG. ACC/AHA/ESC guidelines for the management of patients with atrial fibrillation: a report of the American College of Cardiology/American Heart Association Task Force on Practice Guidelines and the European Society of Cardiology Committee for Practice Guidelines and Policy Conferences (Committee to Develop Guidelines for the Management of Patients with Atrial Fibrillation). Eur Heart J 2001;22:1852-923.

[4] Brand FN, Abbott RD, Kennel WB, Wolf PA. Characteristics and prognosis of lone atrial fibrillation. JAMA 1985;254:3449-53.

[5] Dorian P, Jung W, Newman D, Paquette M, Wood K, Ayers GM, Camm J, Akhtar M, Luderitz B. The impairment of health-related quality of life in patients with intermittent atrial fibrillation: implications for the assessment of investigational therapy. J Am Coll Cardiol 2000;36:1303-9.

[6] Fitzpatrick AP, Kourouyan HD, Siu A, Lee RJ, Lesh MD, Epstein LM, Griffin JC, Scheinman MM. Quality of life and outcomes after radiofrequency His-bundle catheter ablation and permanent pacemaker implantation: impact of treatment in paroxysmal and established atrial fibrillation. Am Heart J 1996;131:499-507.

[7] van den Berg MP, Hassink RJ, Tuinenburg AE, van Sonderen EF, Lefrandt JD, de Kam PJ, van Gelder IC, Smit AJ, Sanderman R, Crijns HJ. Quality of life in patients with paroxysmal atrial fibrillation and its predictors: importance of the autonomic nervous system. Eur Heart J 2001;22:247-53.

[8] Kang Y, Bahler R. Health-related quality of life in patients newly diagnosed with atrial fibrillation. Eur J Cardiovasc Nurs 2004;3:71-6. 
[9] Bubien RS, Knotts-Dolson SM, Plumb VJ, Kay GN. Effect of radiofrequency catheter ablation on health-related quality of life and activities of daily living in patients with recurrent arrhythmias. Circulation 1996;94:1585-91.

[10] Lonnerholm S, Blomstrom P, Nilsson L, Oxelbark S, Jideus L, Blomstrom-Lundqvist C. Effects of the maze operation on healthrelated quality of life in patients with atrial fibrillation. Circulation 2000;101:2607-11.

[11] Dorian P, Paquette M, Newman D, Green M, Connolly SJ, Talajic M, Roy D. Quality of life improves with treatment in the Canadian Trial of Atrial Fibrillation. Am Heart J 2002;143:984-90.

[12] Jenkins LS, Eleanor S, Brodsky M, Mateski D, Chung MK, Rocco TA, Mikel M. Quality of life in patients with atrial fibrillation: baseline data from AFFIRM. Circulation 2000;102:512.

[13] Paquette M, Roy D, Talajic M, Newman D, Couturier A, Yang C, Dorian P. Role of gender and personality on quality-of-life impairment in intermittent atrial fibrillation. Am J Cardiol 2000;86:764-8.

[14] Bygrave AJ, Waktare JEP, Camm AJ, Jung W, Sra J, Dorian P, Paquette M, Wood K. Gender differences in "Quality of life" in atrial fibrillation. J Am Coll Cardiol 1999;33:104A.

[15] Rienstra M, Van Veldhuisen DJ, Hagens VE, Ranchor AV, Veeger NJ, Crijns HJ, Van Gelder IC. Gender-related differences in rhythm control treatment in persistent atrial fibrillation: data of the Rate Control Versus Electrical Cardioversion (RACE) study. J Am Coll Cardiol 2005;46:1298-306.

[16] Savelieva I, Paquette M, Dorian P, Luderitz B, Camm AJ. Quality of life in patients with silent atrial fibrillation. Heart 2001;85:216-7.

[17] Ruo B, Rumsfeld JS, Hlatky MA, Liu H, Browner WS, Whooley MA. Depressive symptoms and health-related quality of life. JAMA 2003; 290:215-21.

[18] Carels RA. The association between disease severity, functional status, depression and daily quality of life in congestive heart failure patients. Qual Life Res 2004;13:63-72.

[19] Mayou RA, Gill D, Thompson DR, Day A, Hicks N, Volmink J, Neil A. Depression and anxiety as predictors of outcome after myocardial infarction. Psychosom Med 2000;62:212-9.

[20] Franche RL, Abbey S, Irvine J, Shnek ZM, Grace SL, Devins GM, Stewart DE. Sex differences in predictors of illness intrusiveness 1 year after a cardiac event. J Psychosom Res 2004;56:125-32.

[21] Cairney J, Terrance JW. The influence of age on gender differences in depression: further population-based evidence on the relationship between menopause and the sex difference in depression. Soc Psychiatry Psychiatr Epidemiol 2002;37:401-8.

[22] Goodwin RD, Gotlib IH. Gender differences in depression: the role of personality factors. Psychiatry Res 2004;126:135-42.

[23] Ong L, Cribbie R, Harris L, Dorian P, Newman D, Mangat I, Nolan R, Irvine J. Psychological correlates of quality of life in atrial fibrillation. Qual Life Res 2006;15:1323-33.

[24] Maglio C, Sra J, Paquette M, Dorian P, Bygrave A, Wood K, Ayers GM. Measuring quality of life and symptom severity in patients with atrial fibrillation. Pacing Clin Electrophysiol 1998;21:839.

[25] Ware JE, Sherbourne CD. The MOS 36-item Short-Form Health Survey (SF-36): conceptual framework and item selection. Med Care 1992;30:473-83.

[26] Ware JE, Kosinski M. SF-36 Physical and Mental Summary Scales: a manual for users of version 1. Lincoln (RI): Quality Metric, 2003.

[27] Zigmond AS, Snaith RP. The Hospital Anxiety and Depression Scale. Acta Psychiatr Scand 1983;67:361-70.
[28] Lowe B, Spitzer RL, Grafe K, Kroenke K, Quenter A, Zipfel S, Buchholz C, Witte S, Herzog W. Comparative validity of three screening questionnaires for DSM-IV depressive disorders and physicians' diagnoses. J Affect Disord 2004;78:131-40.

[29] Snaith RP, Zigmond AS. The Hospital Anxiety and Depression Scale manual. Nelson (Windsor): NFER, 1994.

[30] Bjelland I, Dahl AA, Haug TT, Neckelmann D. The validity of the Hospital Anxiety and Depression Scale. An updated literature review. J Psychosom Res 2002;52:69-77.

[31] Baron RM, Kenny DA. The moderator-mediator variable distinction in social psychological research: conceptual, strategic, and statistical considerations. J Pers Soc Psychol 1986;51:1173-82.

[32] Preacher KJ, Leonardelli GJ. Calculation for the Sobel Test: an interactive calculation tool for mediation tests. Retrieved on October 31, 2003, from http://www.unc.edu/ preacher/sobel/sobel.htm.

[33] Tabachnick BG, Fidell LS. Using multivariate statistics. Boston (MA): Allyn and Bacon, 2001.

[34] Ware JE. How to score the SF-36 Health Survey. Boston (MA): Medical Outcomes Trust, 1994.

[35] Hopman WM, Towheed T, Anastassiades T, Tenenhouse A, Poliquin S, Berger C, Joseph L, Brown JP, Murray TM, Adachi JD, Hanley DA, Papadimitropoulos E. Canadian normative data for the SF-36 Health Survey. Canadian Multicentre Osteoporosis Study Research Group. Can Med Assoc J 2000;163:265-71.

[36] Stordal E, Bjartveit Kruger M, Dahl NH, Kruger O, Mykletun A, Dahl AA. Depression in relation to age and gender in the general population: the Nord-Trondelag Health Study (HUNT). Acta Psychiatr Scand 2001;104:210-6.

[37] Mitchell AR, Spurrell PA, Boodhoo L, Sulke N. Psychosocial aspects of patient-activated atrial defibrillation. J Cardiovasc Electrophysiol 2003;14:812-6.

[38] Martin CR, Lewin RJ, Thompson DR. A confirmatory factor analysis of the Hospital Anxiety and Depression Scale in coronary care patients following acute myocardial infarction. Psychiatry Res 2003; 120:85-94.

[39] Martin CR, Thompson DR, Chan DS. An examination of the psychometric properties of the Hospital Anxiety and Depression Scale in Chinese patients with acute coronary syndrome. Psychiatry Res 2004;129:279-88.

[40] Pedersen SS, van Domburg RT, Theuns DA, Jordaens L, Erdman RA. Concerns about the implantable cardioverter defibrillator: a determinant of anxiety and depressive symptoms independent of experienced shocks. Am Heart J 2005;149:664-9.

[41] Lane D, Carroll D, Ring C, Beevers DG, Lip GYH. Mortality and quality of life 12 months after myocardial infarction: effects of depression and anxiety. Psychosom Med 2001;63:221-30.

[42] Statistics Canada. Legal marital status, age groups and sex for population, for Canada, provinces, territories, census metropolitan areas and census agglomerations, 2001 Census. Retrieved on April 6, 2005, from http://www12.statcan.ca/english/census01/products/ standard/themes/.

[43] Kessler RC, McGonagle KA, Swartz M, Blazer DG, Nelson CB. Sex and depression in the National Comorbidity Survey I: Lifetime prevalence, chronicity and recurrence. J Affect Disord 1993; 29:85-96.

[44] Weissman MM, Bland R, Joyce PR, Newman S, Wells JE, Wittchen HU. Sex differences in rates of depression: cross-national perspectives. J Affect Disord 1993;29:77-84 